\title{
Appointment Keeping Behavior of Medicaid vs. Non-Medicaid Orthodontic Patients
}

Bryan P. Horsley

Virginia Commonwealth University

Follow this and additional works at: https://scholarscompass.vcu.edu/etd

Part of the Orthodontics and Orthodontology Commons

(C) The Author

\section{Downloaded from}

https://scholarscompass.vcu.edu/etd/1521

This Thesis is brought to you for free and open access by the Graduate School at VCU Scholars Compass. It has been accepted for inclusion in Theses and Dissertations by an authorized administrator of VCU Scholars Compass.

For more information, please contact libcompass@vcu.edu. 


\section{School of Dentistry Virginia Commonwealth University}

This is to certify that the thesis prepared by Bryan P. Horsley, DMD entitled APPOINTMENT KEEPING BEHAVIOR OF MEDICAID VS. NON-MEDICAID ORTHODONTIC PATIENTS has been approved by his committee as satisfactory completion of the thesis or dissertation requirement for the degree of Master of Science.

Dr. Steven J. Lindauer, Thesis Director / Program Director Department of Orthodontics

Dr. Omar Abubaker, Committee Member, School of Dentistry

Dr. Bhavna Shroff, Committee Member, School of Dentistry

Dr. Steven J. Lindauer, Chairman Department of Orthodontics, School of Dentistry

Dr. David C. Sarrett, Assistant Dean - Academic Affairs, School of Dentistry

Dr. F. Douglas Boudinot, Dean of the School of Graduate Studies

June 14, 2004 
(C) Bryan P.Horsley, 2004

All Rights Reserved 
APPOINTMENT KEEPING BEHAVIOR OF MEDICAID VS. NON-MEDICAID

\section{ORTHODONTIC PATIENTS}

A thesis submitted in partial fulfillment of the requirements for the degree of Master of Science at Virginia Commonwealth University.

by

BRYAN P. HORSLEY

B.A., Brigham Young University, 1998

D.M.D., University of Louisville School of Dentistry, 2002

Director: STEVEN J. LINDAUER, D.M.D., M.D.SC. PROFESSOR AND CHAIRMAN, DEPARTMENT OF ORTHODONTICS

Virginia Commonwealth University

Richmond, Virginia

June 2004 


\section{$\underline{\text { Acknowledgement }}$}

I would like to thank Dr. Steven J. Lindauer for his direction with this research, his dedication to the specialty of orthodontics, and his leadership in the best residency program ever. Many thanks to Drs. Bhavna Shroff and Omar Abubaker for their examples of ethics and teaching. Thanks to Chad Fowler for performing the statistical analyses and to Blake Maxfield for assisting with the data collection. 


\section{$\underline{\text { Table of Contents }}$}

Acknowledgements .

.. ii

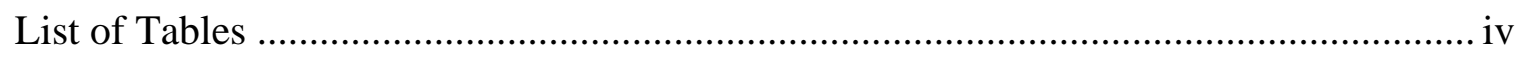

Chapter

1 Introduction ........................................................................................ 1

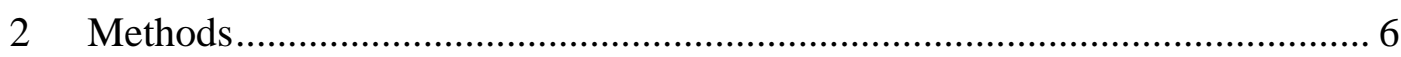

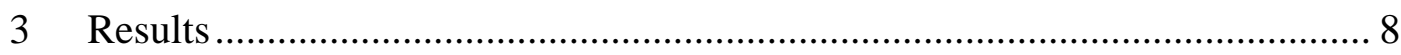

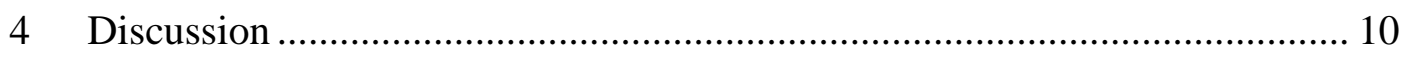

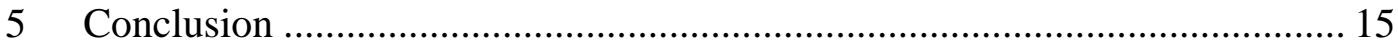

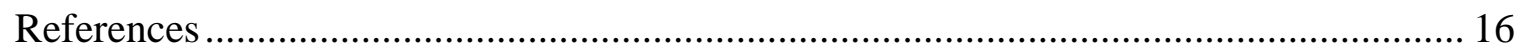




\section{List of Tables}

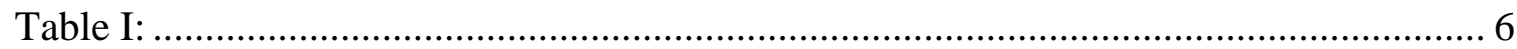

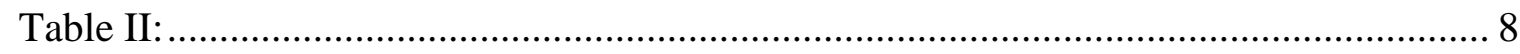

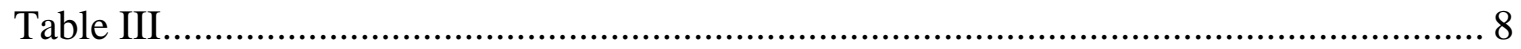

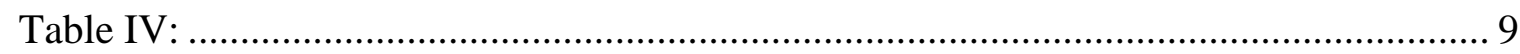

Table V:...................................................................... 10 


\begin{abstract}
$\underline{\text { Abstract }}$
APPOINTMENT KEEPING BEHAVIOR OF MEDICAID VS. NON-MEDICAID

ORTHODONTIC PATIENTS

By Bryan P. Horsley, D.M.D.

A thesis submitted in partial fulfillment of the requirements for the degree of Master of Science at Virginia Commonwealth University.
\end{abstract}

Virginia Commonwealth University, 2004

Major Director: Steven J. Lindauer, D.M.D., M.D.Sc.

Chairman and Professor, Department of Orthodontics

State Medicaid programs were established to care for the poor by eliminating financial barriers and increasing their ability to be treated within the mainstream of the heath care system. The number of children eligible for Medicaid services is increasing, yet the number of Medicaid providers remains low. Health care providers cite failed appointments as being a major problem with Medicaid patients and one of the largest deterrents to participating. The purpose of this study was to determine whether a difference in appointment keeping behavior exists between Medicaid and non-Medicaid orthodontic patients. During a twelve-month period, a tally of appointments was kept for 707 active patients at Virginia Commonwealth University’s Department of Orthodontics. Patients were categorized as either Medicaid or non-Medicaid and their appointment keeping 
behavior was evaluated. The results revealed that a significant difference does exist in the number of failed appointments between the groups $(P<0.0001)$. The Medicaid patients failed 247(15.4\%) of 1609 appointments and non-Medicaid patients failed 367(8.3\%) of 4438 appointments. Additionally, these data show that although Medicaid patients accounted for only $26.6 \%$ of all appointments, they were responsible for about $40 \%$ of all appointment failures. The findings from this study support the concern among dental practitioners that Medicaid patients have higher rate of appointment failures than nonMedicaid patients. 
Introduction

In 1964 less than 1 per cent of the population of this country (1,500,000 persons) was receiving dental treatment under prepaid coverage, according to the Division of Dental Health, United States Public Health Services. ${ }^{1}$ Without dental insurance many people, especially those with low income, were unable to receive dental care. The large percentage of Americans without financial accessibility to dental care and health care became a great concern for the government and, therefore, Medicaid was established in 1965 as Title XIX of the Social Security Act to provide health care to certain low-income individuals. ${ }^{2}$

Since that time accessibility to oral health care has improved due to an increase in dental insurance plans and the advent of the Medicaid program. Despite this, in a report in 2000, U.S. Surgeon General Satcher identified a "silent epidemic” of dental and oral diseases that burden some population groups. He called for a national effort to improve oral health among all Americans. The report identified poor Americans, especially children and the elderly, as the victims of the worst oral health care. ${ }^{3}$ Capilouto identified the same problem in 1988. He stated, "While many herald the decline of diseases and the physiological and psychosocial ravages left in their wake, epidemiological studies show that a disproportionate degree of unmet need still exists among certain segments of the 
population that are more likely to be black, of lower socioeconomic status, and the recipients of little dental care.”4

The most significant public assistance programs designed to improve access to services by low-income persons are the state Medicaid programs. ${ }^{4}$ The goal of these programs is to care for the poor by eliminating financial barriers and increasing their ability to be treated within the mainstream of the heath care system. Mainstreaming is supposed to increase access to services through a wider geographic distribution of service providers. The alternative of providing care at public health clinics limits access geographically depending on the location of the clinics. Unfortunately, substantial evidence shows that access to health service for Medicaid recipients is restricted by providers who are reluctant to participate in the Medicaid program. Provider participation in Medicaid has been declining since at least the mid-1970’s. ${ }^{5}$

The Office of Technology Assessment of the U.S. Congress published a 1990 report reviewing the Medicaid dental programs in seven states and raised serious concerns about the lack of access to dental care for Medicaid-eligible children. ${ }^{2}$ The Virginia Department of Medical Assistance Services (DMAS) stated that the number of children eligible for dental services through Medicaid is on the rise. They reported that in 1993, there were 328,090 eligible children in Virginia of whom less than 20\% received any preventive dental services. $^{6}$ In 1998 that number grew to 370,249 with only 26\% receiving at least one dental visit through Medicaid. The low rate of dentist participation in the Medicaid program is one of the major problems in Virginia and is a key reason why so many eligible children have not received dental care. Dental provider participation in 
Medicaid has been decreasing, yet the number of dentists within the state has continued to rise. DMAS reported 1024 Medicaid providers in 1995 and 646 providers in 2001, nearly a 37\% decrease. Of the 646 participants, only 261 (40\%) provided a significant level of service $(>\$ 10,000)$.

The problem is evident. There is a tremendous need for Medicaid dental services, but there is a lack of Medicaid-participating dentists. A few studies have endeavored to identify why dentist involvement is so low.

In 1990, telephone interviews were conducted with 92 dentists in California by Damiano et al. to determine factors affecting their decisions to participate in the California Medicaid program. ${ }^{5}$ Low fees, denial of payment and broken appointments by patients were identified as the three most important problems with the program. The most often cited problem with the Medi-Cal Program was low fees. A 1996 study conducted in Iowa supported the findings in California. ${ }^{7}$ Dentists cited low fees and broken appointments as the biggest problems with the Iowa Medicaid program.

A 1993 survey sent to 41 pediatric dentists in North Carolina by Venezie et al. showed that seventy-five percent of them limited their Medicaid participation. ${ }^{2}$ Top reasons given for limiting access for new Medicaid patients included low reimbursement rates, broken or canceled appointments, and a need for prior authorization of Medicaid treatment plans.

The Williamson Institute of the Virginia Commonwealth University conducted a study in 1997 by mailing surveys to 688 Medicaid and 1,118 non-Medicaid providers in Virginia. ${ }^{8}$ To ensure a more accurate response, the surveys were evenly distributed to 
dentists across the state. The survey return rate was 57\%. The predominant reason for limited or non-participation was inadequate fees (70\%), followed by broken appointments (51\%) and excessive or complex paperwork (30\%).

A 2001 survey study conducted by Shulmann et al. determined factors associated with Louisiana dentists’ participation in Medicaid. Surveys were mailed to all pediatric and general dentists identified by the Louisiana State Board of Licensing. Fifty percent of the 1,926 surveys sent were returned. The most prevalent reported problem was broken appointments (80\%), followed by low fees (61\%), patient non-compliance (59\%), slow payment (44\%), and complicated paperwork (42\%). ${ }^{9}$

All of these studies identify low reimbursement and broken appointments as being the greatest deterrents for Medicaid participation among dental care providers. Other studies have focused on determining whether a difference truly exists in appointment keeping behavior between Medicaid vs. self-pay patients.

A study conducted in 1969 by DiStasio comparing appointment-keeping behavior of Medicaid and private-pay patients in orthodontic and general dental practices in Massachusetts found that Medicaid patients were more likely to fail appointments than private-pay patients. ${ }^{10}$ A 1977 study conducted by Fazio and Boffa supported DiStasio’s findings. ${ }^{11}$ At the Children’s Hospital Dental Facility in Boston, Massachusetts, they performed a randomized study in which certain variables that led to a "High Risk No Show" behavior among their patients were evaluated. Minorities and those who depended on Medicaid for their source of payment demonstrated a statistically significant association with having a "High Risk No Show" behavior. Their results showed that 73\% of the 
Medicaid patients were likely to fail appointments compared to $30 \%$ of the private-pay patients.

A pediatric office in Pennsylvania evaluated their patients' appointment keeping behavior over 11 weeks. ${ }^{12}$ Lamberth et al. tracked 6314 appointments. $4.1 \%$ of their patient population had Medicaid coverage and made up $7.1 \%$ of the total appointments in their practice. Their results showed that privately insured patients missed 238 (4.1\%) of 5866 appointments and Medicaid-insured patients missed 35 (7.8\%) of 448 appointments. This difference was statistically significant $(P<0.001)$.

A study performed in 2002 by Huie sought to evaluate the appointment keeping behavior of Medicaid Pediatric Dental Patients. ${ }^{13}$ He observed appointment behavior between Medicaid and non-Medicaid patients over a 3 month period. His results showed Medicaid patients had a higher appointment failure rate than those not on Medicaid. The failed appointment rates for Medicaid and non-Medicaid patients were 42\% and 22\% respectively.

No studies have evaluated the appointment keeping behavior of orthodontic patients specifically. The purpose of this study, therefore, was to determine whether a difference exists between Medicaid and non-Medicaid Orthodontic Patients and whether that difference is significant. 
Methods

This retrospective study involved 707 orthodontic patients being treated by orthodontic residents at Virginia Commonwealth University. Patients were classified as “active” orthodontic patients if they were undergoing orthodontic treatment with appliances. Patients in an observation phase or retention were not considered active. All active patients as of July, 2003 were included in the study and they are described in Table

I.

Table I: Description of Subjects

\begin{tabular}{lccc}
$\begin{array}{l}\text { Patient } \\
\text { Classification }\end{array}$ & Male & Female & Total (\%) \\
\hline Medicaid & $79(42.7)$ & $106(52.3)$ & $185(26.2)$ \\
Non-Medicaid & $216(41.4)$ & $306(58.6)$ & $522(73.8)$ \\
All & $295(41.7)$ & $412(58.3)$ & $707(100)$ \\
\hline
\end{tabular}

Patients were categorized as Medicaid or non-Medicaid patients and appointment behavior was evaluated for each group. Non-Medicaid patients were those whose orthodontic treatment was being paid for out-of-pocket or by non-Medicaid third party coverage. Services rendered for Medicaid patients were paid for by state governmentallocated funds. Patient numbers, rather than names, were used to maintain anonymity. The researcher was blinded to whether patients were Medicaid or non-Medicaid during the data collection phase of the study.

Appointments were evaluated as "kept” or "broken”. An appointment was considered "Broken" if the patient failed to show up for the appointment or if the patient canceled on the day of the scheduled appointment. 
All appointments scheduled for one year (August, 2002 - July, 2003) for the 707 active patients were tracked using the clinic’s OPMS database (PracticeWorks, Atlanta, Georgia). Each patient’s appointment keeping history was evaluated individually by manually accessing their individual electronic chart. The total number of appointments scheduled and the total number of failed appointments for each patient were then recorded on a Microsoft Excel spreadsheet to be analyzed statistically.

A Two-Way ANOVA was used $(P<0.05)$ to evaluate whether there was a significant difference in the number of failed appointments between the two patient populations and to analyze the differences in appointment failure rates between the two groups based on the patient's gender. 
Results

\section{$\underline{\text { Overall Differences }}$}

The mean and total number of appointments made, the mean and total number of appointments kept, and the mean and total number of appointments missed for Medicaid and non-Medicaid patients were calculated. These data are included in Table II and Table III.

Table II: Appointment Behavior Characteristics (Means)

\begin{tabular}{|c|c|c|c|c|c|c|c|}
\hline \multirow[t]{2}{*}{$\begin{array}{c}\text { Patient } \\
\text { Classification }\end{array}$} & \multicolumn{2}{|c|}{$\begin{array}{c}\text { Appointments } \\
\text { Made }\end{array}$} & \multicolumn{2}{|c|}{$\begin{array}{c}\text { Appointments } \\
\text { Kept }\end{array}$} & \multicolumn{3}{|c|}{ Appointments Failed } \\
\hline & Mean & SD & Mean & SD & Mean & SD & $95 \% \mathrm{Cl}$ * \\
\hline Medicaid & 8.70 & 2.88 & 7.36 & 2.69 & 1.335 & 1.644 & $\begin{array}{c}(1.097- \\
1.574)\end{array}$ \\
\hline Non-Medicaid & 8.50 & 2.89 & 7.80 & 2.93 & 0.703 & 1.060 & $\begin{array}{c}(0.612- \\
0.794)\end{array}$ \\
\hline All Patients & 8.55 & 2.88 & 7.68 & 2.87 & 0.868 & & \\
\hline
\end{tabular}

Table III: Appointment Behavior Characteristics (Totals)

\begin{tabular}{lccccccc}
\multicolumn{1}{c}{$\begin{array}{c}\text { Patient } \\
\text { Classification }\end{array}$} & \multicolumn{2}{c}{$\begin{array}{c}\text { Appointments } \\
\text { Made }\end{array}$} & \multicolumn{2}{c}{ Appointments } & \multicolumn{2}{c}{ Appointments Failed } \\
& N & \multicolumn{1}{c}{ Pct* $^{*}$} & N & Pct $^{*}$ & N & Pct* $^{*}$ & Rate \\
\hline Medicaid & 1609 & $26.6 \%$ & 1362 & $22.5 \%$ & 247 & $4.1 \%$ & $15.4 \%$ \\
Non-Medicaid & 4438 & $73.6 \%$ & 4071 & $67.3 \%$ & 367 & $6.1 \%$ & $8.3 \%$ \\
All Patients & 6047 & $100.0 \%$ & 5433 & $89.8 \%$ & 614 & $10.2 \%$ & $10.2 \%$ \\
\hline
\end{tabular}

*Percentage of total appointments for all patients.

**Rate based on failures by category.

A two-way ANOVA showed that there was a significant difference in the mean number of appointments missed between Medicaid and non-Medicaid patients $(\mathrm{df}=1$, $P<0.0001)$ 


\section{Differences Between Genders}

The appointment behavior of the two populations, stratified by patient sex, is shown in Table IV.

Table IV: Appointment Behavior Characteristics by Patient Sex

\begin{tabular}{|c|c|c|c|c|c|c|c|}
\hline \multirow{2}{*}{$\begin{array}{c}\text { Patient } \\
\text { Classification }\end{array}$} & \multicolumn{2}{|c|}{$\begin{array}{l}\text { Appointments } \\
\text { Made }\end{array}$} & \multicolumn{2}{|c|}{$\begin{array}{l}\text { Appointments } \\
\text { Kept }\end{array}$} & \multicolumn{3}{|c|}{ Appointments Failed } \\
\hline & $\mathbf{N}$ & Pct $^{*}$ & $\bar{N}$ & Pct $^{*}$ & $\bar{N}$ & Pct $^{*}$ & Rate $^{\star *}$ \\
\hline \multicolumn{8}{|l|}{ Males } \\
\hline Medicaid & 663 & $27.6 \%$ & 581 & $24.2 \%$ & 82 & $3.4 \%$ & $12.4 \%$ \\
\hline Non-Medicaid & 1742 & $72.4 \%$ & 1609 & $66.9 \%$ & 133 & $5.5 \%$ & $7.6 \%$ \\
\hline All Patients & 2405 & $100.0 \%$ & 2190 & $91.1 \%$ & 215 & $8.9 \%$ & $10.4 \%$ \\
\hline \multicolumn{8}{|l|}{ Females } \\
\hline Medicaid & 946 & $26.0 \%$ & 781 & $21.4 \%$ & 165 & $4.5 \%$ & $17.4 \%$ \\
\hline Non-Medicaid & 2696 & $74.0 \%$ & 2462 & $67.6 \%$ & 234 & $6.4 \%$ & $8.7 \%$ \\
\hline All Patients & 3642 & $100.0 \%$ & 3243 & $89.0 \%$ & 399 & $11.0 \%$ & $11.0 \%$ \\
\hline
\end{tabular}

There was a significant difference in mean number of appointments missed by females versus males $(P=0.0018)$. These results are shown in Table V. At a significance level of 0.05 , there were no significant interactions between sex and Medicaid status indicating that differences in appointments missed between Medicaid and non-Medicaid patients was consistent across genders. 
Table V: ANOVA Results

\begin{tabular}{lcrl} 
Source & Df & SS & p-value \\
\hline Medicaid & 1 & 49.15 & $<0.0001^{*}$ \\
Status & & & \\
Sex & 1 & 14.86 & $0.0018^{*}$ \\
Pt Class*Sex & 1 & 4.56 & 0.0836 \\
Error & 703 & 1136.77 & \\
\hline
\end{tabular}




\section{Discussion}

State Medicaid programs have made it possible for low-income persons to have their oral health care treatment needs, including orthodontics, addressed. However, many of these individuals have limited care options based on the lack of participating providers. Studies have shown that the low rate of participation in Medicaid programs by dental practitioners may be linked to poor appointment-keeping behavior.

In this study, the appointment-keeping behavior of Medicaid and non-Medicaid orthodontic patients was evaluated. Using data from 707 active orthodontic patients being treated by orthodontic residents at Virginia Commonwealth University, patient appointments were categorized as "kept" or "broken". The results revealed that there was a significant difference in the number of failed appointments between the groups depending on Medicaid status $(P<0.0001)$. The Medicaid patients failed 247(15.4\%) of 1609 appointments and non-Medicaid patients failed 367(8.3\%) of 4438 appointments. Additionally, these data showed that although Medicaid patients accounted for only 26.6\% of all appointments, they were responsible for about $40 \%$ of all appointment failures with a failure rate of $15.4 \%$.

Appointment-keeping behavior was also compared between male and female patients to determine if gender influenced appointment failures within groups and across groups. Female patients showed a slightly higher failure rate than male patients, 11.0\% versus $10.4 \%$ respectively $(P<0.05)$.

The results of this study, even though conducted on orthodontic patients, are in agreement with previous studies demonstrating that Medicaid patients in general have a 
higher appointment failure rate than non-Medicaid patients. The average broken appointment rate nationwide in Medicaid dental clinics is $30 \%$ according to the American Dental Association. ${ }^{14}$ With such a high appointment failure rate, it is apparent why provider participation is so low. A 1993 survey of Texas dentists showed that 83\% of Medicaid-providers would see more Medicaid patients if they had less broken appointments. ${ }^{15}$ Lamberth stated that broken appointments by Medicaid patients directly impacts the practitioner's decision to accept or not accept Medicaid insurance. ${ }^{12}$ Even though low reimbursement is considered the principal deterrent in accepting Medicaid patients, a missed appointment generates no income. Additionally, a failed appointment is one that could have been used for another patient. Non-participating dentists in North Carolina ranked broken appointments as the second most important reason for not accepting Medicaid insurance. ${ }^{2}$ Reluctant or nonparticipating providers often cite the disutility of "providing care to a population that chronically breaks appointments, fails to comply with treatment recommendations, and places little value on the care it receives.”4

Medicaid was intended not only to increase access for those unable to afford health care, but also to promote delivery of that care in office-based, primary care settings. Limited-provider participation significantly inhibits achievement of both goals. ${ }^{16}$ As a result of the cited problems with Medicaid, the goal of mainstreaming patients is not being met. The distribution of patients is heavily skewed toward a relatively small number of practices with a relatively high percentage of Medicaid patients. Because participating and non-participating dentists have expressed similar concerns about the Medicaid program, it 
is likely that providers will become non-providers in the future if these problems are not addressed. $^{5}$

To be able to address the problem of broken appointments with Medicaid patients, it is important to evaluate the reasons why these patients miss their appointments. Very few studies have attempted to address the reasons for broken appointments. ${ }^{17}$ Walsh et al. conducted a survey in 1967 to discover why patients miss their appointments. The study was conducted on 12,364 patients at the New Orleans Public Health Service Hospital. 1443 (12\%) of these patients were dental patients. There were 840 patients who failed to keep their appointments during a 6 week period. Questionnaires were sent to 734 of them to learn why appointments had been missed. The most cited reasons for failing appointments were communication failure (23\%), geographical separation (20\%), forgot (11\%), illness (20\%) and transportation problems (7\%). Hoffmann and Rockart performed a similar study in 1969 at the Massachusetts General Hospital in Boston. ${ }^{18}$ The results were similar. They found $34 \%$ of the patients failed their appointments due to communication problems, $18 \%$ due to illness, $14 \%$ forgot their appointment, $8 \%$ due to distance, and 7\% had a difficulty with transportation. These issues must be addressed to maintain the current providers and encourage increased participation by non-providers.

Solutions to improve appointment keeping behavior to increase providerparticipation must be reached, yet may vary from state to state and person to person. Fazio and Boffa suggested that care should not be totally free and that the Medicaid patient should have some investment in his or her care. ${ }^{11}$ They felt that some minimal out-ofpocket expense should diminish "No Show" behavior because, without a financial 
investment, the patient is not motivated to keep appointments. Educating Medicaid patients about the importance of keeping scheduled appointments was their other solution. Capilouto suggested that policy makers require doctors to agree to accept Medicaid patients to become licensed. ${ }^{4}$ A more favorable income tax rate as practices increase their Medicaid populations was another of his suggestions. He emphasized that deferred dental treatment often results in more expensive care and unattended dental problems diminish health and the quality of life.

Virginia’s solution to the problem was the formation of the Dental Advisory Committee to advise the Virginia Department of Medical Assistance Services (DMAS) on how to increase provider participation in Medicaid and address problems such as low reimbursement rates, claims processing, pre-authorization, and failed appointments. ${ }^{6}$ The advisory committee encourages dentists from across the state to give input on how to improve the Medicaid program and increase participation. A proposal to remove preauthorization requirements for dental services for children under 21 is under consideration. With determination from each state to improve its Medicaid program, changes can be made and provider-participation can increase. 


\section{Conclusions}

This study evaluated the differences in appointment-keeping behavior between Medicaid and non-Medicaid orthodontic patients. Data from electronic charts of orthodontic patients at Virginia Commonwealth University were audited for all active patients over a period of one year $(n=707)$. Appointments were categorized as "kept" or “broken” based on the patient failing to present for an appointment or a same-day cancellation of an appointment. Patients were categorized as Medicaid or non-Medicaid patients and gender was recorded.

There was a statistically significant difference in the number of appointment failures between Medicaid and non-Medicaid patients $(P<0.0001)$. Medicaid patients exhibited a higher failure rate (15.4\%) than non-Medicaid patients (8.3\%). Although within-group gender differences were not significant, across-group differences showed that females had slightly higher failure rates than males $(P<0.05)$.

The findings from this study support the concern among dental practitioners that Medicaid patients have higher appointment-failures than non-Medicaid patients. Future research might focus on determining the factors contributing to the poor appointment behavior in this group of patients and on what solutions might be successful in improving appointment attendance. 


\section{Literature Cited}

1. Salzmann JA. Orthodontics under Medicare and Medicaid. Am J Orthod 1966;52:922-926.

2. Venezie RD, Vann WF, Cashion SW, Rozier G. Pediatric and general dentists' participation in the North Carolina Medicaid program: trends from 1986 to 1992. Pediatr Dent 1997;19:114-117.

3. U. S Department of Health and Human Services. Oral Health in America: A report of the Surgeon General-Executive Summary. Rockville, MD: U.S. Department of Health and Human Services, National Institute of Dental and Craniofacial Research, NIH, 2000; 1,5-6

4. Capilouto E. The dentist's role in access to dental care by Medicaid recipients. J Dent Educ 1988;52:647-52.

5. Damiano PC, Brown R, Johnson JD, Scheetz JP. Factors Affecting Dentist Participation in a State Medicaid Program. J Dent Educ 1990;54:638-643.

6. Commonwealth of Virginia Department of Medical Assistance Services, For Improving Access to Children’s Oral Health Services. October 2001

7. Damiano PC, Kanellis MJ, Willard JC, Momany ET. A Report of the Iowa Title XIX Dental Program. The Public Policy Center at the University of Iowa, Iowa City, IA 1996.

8. The Williamson Institute for Health Studies. A Study of Dentists Participation and Payment Rate for the Medicaid in Virginia. September 1997.

9. Shulman JD, Ezemobi EO, Sutherland JN, Barsley R. Louisiana dentists attitudes toward the dental Medicaid program. Pediatr Dent 2001;23:395-400.

10. Di Stasio JG. The Occurrence of "no show” appointments among Medicaid and private dental patients. J Mass Dent Soc 1969;18:82-84.

11. Fazio RC, Boffa J. A study of “broken appointment” patients in a children's hospital dental clinic. J Dent Res 1977;56:1071-1076.

12. Lamberth EF, Rothstein EP, Hipp TJ, Souder RL, Kennedy TI, Faccenda DF, Casher D, Kratz

RT,Homeier BP. Rates of missed appointments among pediatric patients in a private practice: Medicaid compared with Private Insurance. Arch Pediatr Adolesc Med 2002;156:86-87.

13. Huie, MA. Appointment Keeping Behavior of Medicaid Pediatric Dental Patients. Thesis at Virginia Commonwealth University, 2002.

14. Brysh LS. “Where’s My Patient?” A plan to decrease broken appointments in a predominantly Medicaid clinic. Spec Care Dentist 2001;21:126-128.

15. Porteous NB. Provider Input for Improvement of the Early and Periodic Screening, Diagnosis and Treament (EPSDT) Program in Texas. A Report form the University of Texas Health Science Center at San Antonio, Department of Community Dentistry, San Antonio, TX 1994.

16. Davidson SM: Physician participation in Medicaid: background and issues. J Health Polit Policy Law 1982;6:703-717.

17. Walsh JJ, Benton JL, Arnold JG. Why patients break appointments. Hosp Top 1967;45:67-72.

18. Hoffman PB, Rockart JF. Implication of the no-show rate for scheduling OPD appointments. Hosp Prog 1969;50:35-40. 


\section{VITA}

Dr. Bryan P. Horsley was born in Montpelier, Idaho on November 28, 1973. He received a Bachelor of Arts degree in Portuguese with a minor in Chemistry from Brigham Young University in 1998. He attended The University of Louisville School of Dentistry and earned his DMD degree in 2002. He began his orthodontic residency program at Virginia Commonwealth University that same year. He is blessed with a beautiful and supportive wife, Jennifer, and 3 wonderful daughters. 